\title{
Reflection and Metacognition in an Introductory Circuits Course
}

\section{Dr. Stephanie Claussen, Colorado School of Mines}

Stephanie Claussen's experience spans both engineering and education research. She obtained her B.S. in Electrical Engineering from the Massachusetts Institute of Technology in 2005. Her Ph.D. work at Stanford University focused on optoelectronics, and she continues that work in her position at the Colorado School of Mines, primarily with the involvement of undergraduate researchers. In her role as an Associate Teaching Professor, she is primarily tasked with the education of undergraduate engineers. In her courses, she employs active learning techniques and project-based learning. Her previous education research, also at Stanford, focused on the role of cultural capital in science education. Her current interests include the study of engineering students' development of social responsibility and the impact of students' backgrounds in their formation as engineers.

\section{Dr. Vibhuti Dave, Colorado School of Mines}

Dr. Vibhuti Dave joined Penn State Erie, The Behrend College as an Assistant Professor in the Electrical, Computer, and Software Engineering program in Fall 2007. She received her undergraduate engineering degree in the field of Electronics and Communication from Nirma Institute of Technology, India in 2000. She received her M.S. in Electrical Engineering and Ph.D. (2007) in Computer Engineering from the Illinois Institute of Technology, Chicago, IL.

Dr. Dave's research interests lie in the field of High Speed Computer Arithmetic and Computer Architecture. Her research has been focused on the design high-speed multi-operand adders. In addition, she is also interested in performing research in VLSI implementation of signal processing algorithms, and low power integrated circuit design.

Her teaching interests include Digital Logic Design, Computer Architecture, Computer Arithmetic, VLSI Design. 


\section{Reflection and Metacognition in an Introductory Circuits Course}

\section{Introduction}

There are increasingly frequent calls to incorporate reflection into engineering education. Much of the focus has been on the use of reflection in teaching design. ${ }^{1,2}$ However, there have also been efforts to incorporate reflective practices into courses which are not specifically focused on design. If we are able to incorporate reflection into what "the students learn engineering to be" 3 -meaning, the engineering science courses which make up the vast majority of most undergraduate curricula - reflection is expected to contribute to learning outcomes and students' development of metacognitive and social skills. ${ }^{4}$

Because exams are generally used for formative assessment, they are rarely also leveraged as an opportunity for students to measure their learning with an eye toward improvement, which presents an opportunity to also develop reflection skills. A few researchers have previously developed assignments in which students reflect on their exam performance and characterize the errors that were made. ${ }^{5,6}$ However, a systematic comparison of the learning achieved by students who complete exam reflection exercises and a comparable group of students who complete a control exercise has not been previously done.

To encourage students to reflect on their exam errors, we have adapted Benson and Zhu's tool, ${ }^{6}$ which they refer to as the Exam Analysis and Reflection (EAR) procedure, in an introductory electrical circuits course. In their work, Benson and Zhu ask students to respond to three reflection prompts for each question they got wrong on an exam. The prompts lead the students through identifying and analyzing the mistakes they made and proposing what they can do to avoid similar issues in the future.

This study employs the EAR in a large introductory course for non-majors. The multi-section, multi-instructor nature of the course provides a natural platform for building upon Benson and Zhu's work. This study began in the fall of 2015. Over the three semesters since it began, we have split the sections of the course into an intervention group, where the adapted EAR process is followed after each exam, and a control group, in which students are given the option of extra credit by solving an additional problem. In two instances, we had a control section and intervention section both taught by the same instructor in the same semester, which provides particularly rich comparison data.

We have collected data related to student participation, the quality of their work in both the control and the interventions, and the scores on their final examination. Initial analysis does not show that this intervention led to improved performance on the final exam. We suspect that this may be due to the nature of the intervention-namely, that it was infrequent (twice over the course, corresponding to the two midterm exams) and was offered as optional extra credit. Additional experimental design issues are also discussed. 


\section{Background}

The context for this work is an introductory circuits course, a venue which has seen increased attention from researchers in recent years. For example, in 2016 Gero et al. published their work on increasing the motivation of students in an introductory circuits course by deliberately incorporating “real world," electrical engineering examples into the course. ${ }^{7}$ Their results showed a significant increase in the intrinsic motivation of students in the course, compared to those who did not take this version of the course. Pitterson et al. have researched how conceptual understanding is facilitated through active learning strategies in an introductory circuits course. ${ }^{8}$ Much work has been done in the area of innovative laboratory setups, hands-on experiments, or simulation tools to supplement or assist the teaching of introductory. ${ }^{9-11}$ The research presented in this paper is focused on the impact of a short, reflection-based intervention on student understanding and performance in such a course. We believe that the results and conclusions described here can readily be translated to other courses and engineering disciplines, and thus, the remainder of our paper works within the context of undergraduate engineering courses broadly.

Learning from past experiences is intuitive and practiced by most people on a day-to-day basis. However, in engineering classrooms, such deliberate practice, though a growing trend, remains a significant challenge. Instructors traditionally provide assessments such as homework assignments, exams, and projects as indicators of student performance and understanding. Instructor feedback on graded work is meant to help students spot their mistakes and reflect on their learning, so that they can avoid such mistakes in the future. However, students frequently only glance at instructor feedback and give brief attention to mistakes they make on formative assessments, which can lead to repeating the mistake again in the future and failing to learn from such experiences.

The motivation to incorporate reflection into higher education coursework stems from pedagogical research suggesting that students need to put meaning to experience to become successful professionals. As Dixon explains, "Experience per se does nothing for designers - or anyone else - unless they learn something cognitive in the process". ${ }^{12}$ As suggested by Mitchell et al., it is important for a practitioner to be proactive about incorporating experience into planning, with emphasis on the word proactive. ${ }^{13}$ Traditional exams and assignments with some instructor feedback do not provide many opportunities for a student to be proactive about learning from their mistakes. This can be exasperated when a student is frustrated by a bad score or unmotivated to put in the additional work required to improve.

The importance of reflection in engineering education has been well established. ${ }^{4,14,15}$ Such studies have aimed to make reflection a student-centered activity in engineering courses of different levels, in an attempt to make students more aware of what they have learned and to go beyond scores on an exam or homework assignment. Adams et al. utilized Schon's reflective practitioner theory as a lens to understand and measure reflective practitioner behavior in engineering students engaged in design activities. ${ }^{1,16}$ Chen proposed using online tools such as 
Wikis and Weblogs and a technique called Folio Thinking, to support reflective learning in an introductory engineering design course. ${ }^{17}$ Folio Thinking is a pedagogical approach where students create learning portfolios, with the end goal being to enhance students' self-awareness of their knowledge by making it explicit and visible for themselves as well as for others. Turns et al. specifically focus on reflection on experience as an intentional thinking process. ${ }^{1}$ They point out that, in order for reflection to have any impact on future action, the individual has to revisit their past, and use one or more lenses to assign meaning to the experience. McKenna et al. went a step further by focusing on faculty members instead of students, discussing collaborations between engineering faculty and learning sciences researchers, and placing an emphasis on collaborative reflection. ${ }^{15}$ They used collaborative reflection between faculty members to improve teaching.

Wynne et al. examined the perceived benefits of reflective activities such as recitation discussions and journaling by the students. ${ }^{5}$ The authors employed traditional teaching methods and unconventional reflection techniques in an engineering course to find out which activities were most helpful to the learning process from the students' perspective. Of particular interest from this study is the use of an exam journal. With the exam journal, they aimed to address the dilemma regarding the value of learning versus students' obsession with grades. Students were required to re-work incorrectly answered problems on their exam, and explain their thought process when they did the problem on the exam. The journals were meant to be used by students to address any academic weaknesses as indicated by exam results. It was found that the journals helped reinforce concepts that would appear on the final exam and led to the reduction of tension in the classroom atmosphere since they were seen as means of grade redemption. The journals also helped instructors determine the learning needs of the students.

Benson and Zhu took an approach along the same lines to bridge the gaps in knowledge and understanding. ${ }^{6}$ They used a more guided approach when introducing self-assessment activities in two of their mechanical engineering courses. Students did a self-assessment after each exam, reflecting on each problem that they got wrong and describing actions that needed to be taken to improve performance in the future. An additional step was to categorize their errors within a predefined set of categories: Mathematical Component, Problem Solving Component, and Engineering Component. Implementation of this pedagogical approach in an "Introduction to Engineering Course" exposed a number of serious gaps in skills that instructors take for granted from students in an engineering course at this level. Information gained by faculty from their students' performance helped with continuous improvement methods for the course. The faculty also observed that reflective thinking needs to be nurtured, encouraged and taught, as it is not an implicit skill. In a slightly more advanced class on "Solid Mechanics", they saw that the guided reflection exercise could be a useful tool in helping struggling students improve and focus. Though this activity did provide students with an opportunity to pause and reflect on the possible cause of errors as opposed to receiving a low performance grade and quickly moving on, the authors did not reach a conclusion as to whether the reflection exercise helped the students repair knowledge gaps. Instead, the quantitative data they collected focused on the student categorization of errors and which students chose to participate in the reflection exercise. 
The work presented in this paper builds on that done by Wynne et al. and Benson and Zhu by giving students the time, incentive and opportunity to reflect on exam problems where they have lost points, and in the process leverage their exam performance to learn in a more deliberate and intentional manner. With this study, an attempt has been made to compare the performance of students incentivized to go through this guided self-assessment process with students who completed a control exercise which was not related to reflection and metacognition.

\section{Methods}

The research presented in this paper was implemented in a 3 credit hour course, "Introduction to Electrical Circuits," which has unique characteristics that make it a good choice for this study. It is a course taken by non-majors (mostly Mechanical Engineers). It is taught in multiple sections with each section consisting of an average of $40-50$ students. It is also taught by multiple instructors, all electrical engineering faculty or adjunct faculty.

Although each section is independently "owned" by its instructor, there is a course coordinator who formulates the syllabus, sets the schedule, designs the homework assignments and exams, and determines the final grading scheme of the course ensuring that all students are learning the material at the same pace. The structure of the course has remained largely unchanged over many years. A common textbook is used across all sections. Each section meets for 50 minutes three times a week. Students from all sections are assigned the same homework assignments and take the same exams at common times during the course of the semester. The pedagogical approaches used by instructors to deliver the material are not set by the course coordinator, which means that each section is likely taught in a unique way (unless an instructor has been assigned to two different sections). Each semester, there are about 200 students (all non-EE majors) who go through this course, either because it is a required course for their degree, or because they intend to get a minor in Electrical Engineering. The student demographic is mainly comprised of sophomore level Mechanical Engineering students, with a handful of Mining and Petroleum Engineering majors who range from sophomores to seniors. Considering the characteristics of this population and anecdotal feedback, most students do not view this course as something they want to take but something they need to take to fulfill a requirement.

Over the course of the semester, students take two midterm exams and a final exam, each worth $25 \%$ of their final grade. Because the exams are so heavily weighted, they can cause anxiety for students. The midterm exams in this class are a combination of multiple choice and free response questions. There are generally 12 multiple choice questions, each worth 4-5 points. Each midterm also consists of two multiple-choice questions, which are worth the remaining points. The final exam is entirely multiple choice. All exams were scored out of 100 points.

Data collection for this study started in Fall 2015, when four sections of this course were offered. Of the four sections, two sections were taught by the same instructor, who also the course coordinator that semester (Prof. X), while the other two were taught by different instructors (Prof 
Y and Prof. Z). We divided the sections into two intervention groups and two control groups. Table 1 shows how each section was assigned and its corresponding enrollments.

Table 1: Section Details for Fall 2015

\begin{tabular}{|c|c|c|c|}
\hline Section & Instructor & Enrollment & Category \\
\hline A & Prof Y & 50 & Control \\
\hline B & Prof Z & 22 & Intervention \\
\hline C & Prof X & 44 & Control \\
\hline D & Prof X & 48 & Intervention \\
\hline
\end{tabular}

Specifics of the control and intervention groups are discussed in the following section.

In Spring 2016, five sections of the class were offered. Table 2 shows some details for Spring 2016. Table 3 shows similar details for Fall 2016 when Prof. Z coordinated and instructed two sections.

Table 2: Section Details for Spring 2016

\begin{tabular}{|c|c|c|c|}
\hline Section & Instructor & Enrollment & Category \\
\hline A & Adjunct A & 57 & Intervention \\
\hline B & Prof X & 57 & Intervention \\
\hline C & Prof Z & 58 & Intervention \\
\hline D & Adjunct B & 56 & Intervention \\
\hline E & Adjunct B & 29 & Intervention \\
\hline
\end{tabular}

Table 3: Section Details for Fall 2016

\begin{tabular}{|c|c|c|c|}
\hline Section & Instructor & Enrollment & Category \\
\hline A & Prof. W & 11 & Control \\
\hline B & Prof Z & 39 & Control \\
\hline C & Prof Z & 49 & Intervention \\
\hline D & Prof X & 28 & Intervention \\
\hline
\end{tabular}

The two midterm exams were graded and returned within one week of the scheduled exam date. All instructors complied with this rule for fairness. Multiple choice questions were awarded no partial credit. The students could earn partial credit on the free response questions. A detailed grading rubric was developed for the free response questions to ensure consistency in grading between different sections.

For this study, during the class period when exams were returned, instructors announced the opportunity to earn extra credit through an optional additional assignment, which took the form of either the intervention or a control assignment. Both exercises were worth ten points of extra credit which was added to their exam scores. This assignment was administered for both midterms during the semester. 
As seen in Tables 1-3 above, during two semesters when both a control and an intervention were run (Fall 2015 and Fall 2016), it was decided to use the sections with larger enrollment numbers as intervention groups and the others as control groups in an attempt to get a sufficient sample size. One semester (Spring 2016), only the intervention was administered.

\section{Intervention Groups}

The intervention assignment was closely modeled after the Exam Analysis and Reflection (EAR) exercise created by Benson and Zhu. ${ }^{6}$ In it, students were asked to reflect on two problems they answered incorrectly on the exam. Since the free response questions are the ones where students are required to show their work in order to receive partial credit, these are the exam questions students were required to select first for their reflection. If they missed between zero and three points on the free response questions (out of between 20 and 26 available points, depending on the exam), then they were asked to reflect on a multiple choice question that they got wrong. Each question they reflected on was worth up to five points of extra credit.

The students were asked to complete two tasks in their reflection for each problem. The first task was answering three prompts from Benson and Zhu:

- How is my solution different from the solution provided?

- What went wrong with my solution?

- How can I use this information (i.e. what strategy can I use to improve my performance on a similar problem in the future?

They were also asked to identify the type of error (mathematical, conceptual, etc.) they had made using a table of categories of errors from Benson and Zhu. In Appendix A, a sample reflection and a list of common mistakes, both of which were provided to the students, are provided.

In order to comply with Institutional Review Board (IRB) standards, each student was asked to sign a consent form where they elected to either join the research study or opt out of it. Students were made aware that this decision did not affect the opportunity to earn extra credit and did not affect their grade in any way. Data from students who chose not to participate in the study has not been used for the analysis presented here. In order to ensure that no bias was introduced on the part of the instructors or graders, this data was either graded by someone other than the section instructor or anonymized before the reflection assignments were graded. The extra credit points students received were added to their raw exam score so that the instructors (two of whom are the authors on this paper) could not see which students had elected to do the extra credit and who had not. Since each exam was worth a total 100 points, the maximum score that a student could receive on their exam, including the extra credit, was capped at 100.

\section{Control Groups}

In the control assignment, students were also given an opportunity to earn ten extra points on each exam by completing an extra credit problem similar to the free response problems on the test. Again, in order to comply with IRB standards, students were asked to sign a release form, data was anonymized and a detailed grading rubric was used to ensure fairness and a common 
benchmark. Data from students who chose not to participate in the study has not been used for analysis.

\section{Analysis}

This work attempted to quantitatively evaluate Benson and Zhu's Exam Analysis and Reflection (EAR) intervention to determine if this simple exercise could improve student understanding and retention of circuits knowledge, as measured on the final exam. Our primary research question for this work was:

Did the students who completed the EAR fare better on the final exam than those who did not complete it?

To answer this question, we compared two sets of data:

A) Control vs. intervention, consistent instructor: There were two instances when one instructor taught two sections of the course during the same semester (Fall 2015 with Prof. X and Fall 2016 with Prof. Z), which allowed us to make a direct comparison between the control and intervention.

B) Control vs. intervention across all sections and instructors: We also set out to see if the intervention could lead to improved student outcomes across all sections taught by diverse instructors. In other words, was the intervention successful enough to make up for other factors, such as variation in instructor quality? To explore this, we looked at data from all sections taught during both semesters of the 2015-2016 academic year, since the final exam was identical across all sections and the two semesters. As seen in Tables 1 and 2, the control was administered in two sections $(N=79)$, and the intervention was administered in seven sections $(N=194)$.

Only students who completed the EARs or control problems after each of the two midterm exams during the semester were included in our analysis. Any student who did not consent to be a part of the study (on average, approximately fewer than $10 \%$ of students who completed the extra credit did not consent to the study) were also removed from the data set.

We analyzed the two sets of data listed above in three different ways:

1. We compared the mean final exam scores of students who completed the control and those who completed the intervention.

2. In order to analyze the impact the intervention had on improving student performance over the course of the semester, we created an "improvement score" for all participants, which was calculated as the difference between a student's final exam score and the average of their scores on the two midterms.

3. We isolated the data for the participants in the upper (Q3 and Q4) and lower (Q1 and Q2) halves of each population (as determined by their scores on the first midterm), to see if 
the students who initially succeeded or struggled in the course particularly benefited from the intervention.

We calculated z-statistics for the comparisons above when applicable (per the Central Limit Theorem, $N>30$ ), ${ }^{18}$ to see if any improvements that were made in the intervention group were statistically significant. When $N$ was less than 30 , t tests were used for comparison. We used an alpha level of .05 for all statistical tests. Relevant effect sizes were also calculated using Cohen's $d$. The results are presented below.

\section{Results}

As seen in Table 4, when comparing the two sections Prof. X taught in the Fall of 2015 - one of which completed the intervention and one of which completed the control extra credit problem there was no statistically significant improvement in the performance of students on the final exam among those who did the $\operatorname{EAR}(t(54)=0.685, P>.4$; Cohen's $d=0.186)$. There was also no statistically significant increase in the amount of improvement between the midterm scores and final exam scores of the students in the intervention $(t(54)=0.220, P>.4$; Cohen's $d=$ $0.06)$.

Results from the bottom two quartiles of each section were looked at separate from the remainder of the data, with the belief that it was perhaps the students who were performing worse in the course who would most benefit from a reflection exercise like the EAR. However, when only the bottom two quartiles of each section were considered for Prof. X, there was no statistically significant improvement in the final exam performance of the students in the intervention section as compared with the control section $(t(27)=0.54, .4>P>.25$; Cohen's $d=$ $0.20)$. The control section actually improved slightly more between the midterm and final exam than the intervention section (a difference of 0.2 points; Cohen's $d=0.02$ ), so no statistical analysis was done to compare these two means.

For completion, the upper two quartiles were also analyzed, to see if initially higher-performing students benefited from the EAR. While the students in the intervention section again fared better on the final and showed more improvement on the final than the students in the control section, it was not a statistically significant difference $(t(25)=0.65, .25>P>.1$, Cohen's $d=$ 0.25 for the final exam scores, $t(24)=0.69, .25>P>.1$, Cohen's $d=0.27$ for the improvement in scores).

When analyzing the two sections which Prof. Z taught in the Fall of 2016, it appears that the control section may have been a stronger section overall than the intervention section, as demonstrated by the fact that their exam score averages were consistently higher throughout the semester (both midterm exams and the final exam). Cohen's $d$ was calculated for all participants in the two sections to be 0.51 , one of the largest effect sizes seen in this study. The control 
Table 4: Means and standard deviations on the final exam and improvement scores for students in the control and intervention groups

\begin{tabular}{|c|c|c|c|c|c|}
\hline & & $\begin{array}{c}\text { Mean, standard } \\
\text { deviation and } \\
\text { sample size } \\
\text { (Final exam, } \\
\text { control) }\end{array}$ & $\begin{array}{c}\text { Mean, standard } \\
\text { deviation and } \\
\text { sample size } \\
\text { (Final exam, } \\
\text { intervention) }\end{array}$ & $\begin{array}{c}\text { Mean, standard } \\
\text { deviation and } \\
\text { sample size } \\
\text { (Exam } \\
\text { improvement }^{1} \text {, } \\
\text { control) } \\
\end{array}$ & $\begin{array}{l}\text { Mean, standard } \\
\text { deviation and } \\
\text { sample size } \\
\text { (Exam } \\
\text { improvement }{ }^{1} \text {, } \\
\text { intervention) } \\
\end{array}$ \\
\hline \multirow{3}{*}{$\begin{array}{l}\text { Data Set 1A: } \\
\text { Control vs. } \\
\text { intervention, } \\
\text { Prof. X } \\
\text { (Fall 2015) }\end{array}$} & $\begin{array}{c}\text { All } \\
\text { participants }\end{array}$ & $\begin{array}{c}\bar{X}=75.4 \\
s=12.9 \\
N=30\end{array}$ & $\begin{array}{c}\bar{X}=77.8 \\
s=12.8 \\
N=27\end{array}$ & $\begin{array}{c}\bar{X}=6.0 \\
s=10.9 \\
N=30\end{array}$ & $\begin{array}{c}\bar{X}=6.6 \\
s=10.1 \\
N=27\end{array}$ \\
\hline & $\begin{array}{l}\text { Q1 and Q2 } \\
\text { only }^{2}\end{array}$ & $\begin{array}{c}\bar{X}=67.5 \\
s=11.1 \\
N=16\end{array}$ & $\begin{array}{c}\bar{X}=69.8 \\
s=11.7 \\
N=14\end{array}$ & $\begin{array}{c}\bar{X}=8.8 \\
s=12.7 \\
N=16\end{array}$ & $\begin{array}{c}\bar{X}=8.6 \\
s=12.9 \\
N=14\end{array}$ \\
\hline & $\begin{array}{l}\text { Q3 and Q4 } \\
\text { only }\end{array}$ & $\begin{array}{c}\bar{X}=84.5 \\
S=8.1 \\
N=14\end{array}$ & $\begin{array}{c}\bar{X}=86.4 \\
s=7.1 \\
N=13\end{array}$ & $\begin{array}{l}\bar{X}=2.7 \\
S=7.5 \\
N=14\end{array}$ & $\begin{array}{l}\bar{X}=4.5 \\
S=5.6 \\
N=13\end{array}$ \\
\hline \multirow{3}{*}{$\begin{array}{l}\text { Data Set 1B: } \\
\text { Control vs. } \\
\text { intervention, } \\
\text { Prof. Z } \\
\text { (Fall 2016) }\end{array}$} & $\begin{array}{c}\text { All } \\
\text { participants }\end{array}$ & $\begin{array}{c}\bar{X}=64.3 \\
s=10.1 \\
N=29\end{array}$ & $\begin{array}{c}\bar{X}=59.3 \\
S=9.4 \\
N=22\end{array}$ & $\begin{array}{c}\bar{X}=-11.7 \\
s=10.0 \\
N=29\end{array}$ & $\begin{array}{c}\bar{X}=-11.1 \\
s=11.51 \\
N=22\end{array}$ \\
\hline & $\begin{array}{l}\text { Q1 and Q2 } \\
\text { only }^{2}\end{array}$ & $\begin{array}{c}\bar{X}=61.0 \\
s=9.1 \\
N=15\end{array}$ & $\begin{array}{c}\bar{X}=54.5 \\
S=7.9 \\
N=11\end{array}$ & $\begin{array}{c}\bar{X}=-9.3 \\
s=10.6 \\
N=15\end{array}$ & $\begin{array}{c}\bar{X}=-3.7 \\
s=8.5 \\
N=11\end{array}$ \\
\hline & $\begin{array}{l}\text { Q3 and Q4 } \\
\text { only }\end{array}$ & $\begin{array}{c}\bar{X}=67.9 \\
S=2.7 \\
N=14\end{array}$ & $\begin{array}{c}\bar{X}=64.1 \\
S=8.5 \\
N=11\end{array}$ & $\begin{array}{c}\bar{X}=-14.3 \\
S=8.9 \\
N=14\end{array}$ & $\begin{array}{c}\bar{X}=-19.4 \\
S=8.2 \\
N=11\end{array}$ \\
\hline \multirow{3}{*}{$\begin{array}{l}\text { Data Set 2: } \\
\text { Control vs. } \\
\text { intervention, } \\
\text { all sections } \\
(2015-2016)\end{array}$} & $\begin{array}{c}\text { All } \\
\text { participants }\end{array}$ & $\begin{array}{c}\bar{X}=76.6 \\
s=12.0 \\
N=79\end{array}$ & $\begin{array}{l}\bar{X}=72.2 \\
s=11.8 \\
N=194\end{array}$ & $\begin{array}{c}\bar{X}=7.86 \\
s=11.0 \\
N=79\end{array}$ & $\begin{array}{l}\bar{X}=0.7 \\
S=12.4 \\
N=194\end{array}$ \\
\hline & $\begin{array}{l}\text { Q1 and Q2 } \\
\text { only }^{2}\end{array}$ & $\begin{array}{c}\bar{X}=70.2 \\
s=11.5 \\
N=41\end{array}$ & $\begin{array}{l}\bar{X}=66.9 \\
s=12.3 \\
N=101\end{array}$ & $\begin{array}{c}\bar{X}=12.1 \\
s=11.6 \\
N=41\end{array}$ & $\begin{array}{l}\bar{X}=5.3 \\
S=13.4 \\
N=101\end{array}$ \\
\hline & $\begin{array}{l}\text { Q3 and Q4 } \\
\text { only }\end{array}$ & $\begin{array}{c}\bar{X}=83.5 \\
S=8.0 \\
N=38\end{array}$ & $\begin{array}{c}\bar{X}=78.0 \\
S=8.0 \\
N=92\end{array}$ & $\begin{array}{l}\bar{X}=3.3 \\
S=8.5 \\
N=38\end{array}$ & $\begin{array}{c}\bar{X}=-4.3 \\
S=8.9 \\
N=92\end{array}$ \\
\hline
\end{tabular}

problem which the students did in the control section after each exam seems highly unlikely to have led to improved student outcomes, considering that students completed hundreds of similar problems over the course of the semester. Because of this difference in the student makeup of the

\footnotetext{
${ }^{1}$ Improvement scores were defined as the difference between a student's final exam score and the average of their two midterm exams.

${ }^{2}$ In places, the number of participants in Q1 and Q2 is slightly higher than half of the total number of participants in that group. This is because all students who achieved the median score on the midterm were included in this group (sometimes multiple students earned the median score).
} 
two sections, the improvement score was the focus of this analysis, with the hypothesis that students in the intervention section improved more between the midterms and finals than students in the control section. (Note that the final exam used in the Fall of 2016 was much harder than the final exam used in the 2015-2016 academic year. Hence, the mean improvement scores were consistently negative across all instructors and all sections, as students on average fared worse on the final than they did on the midterms.) While the mean improvement was higher in the intervention as compared with the control, it was not statistically significant $(t(41)=$ 0.199, $P>$.4; Cohen's $d=0.06)$.

When only looking at the bottom two quartiles of each of Prof. Z's sections, students in the intervention section improved significantly more than students in the control section (though noting that, again, such "improvement" scores were negative due to a challenging final exam). However, this difference in means on the improvement score did not quite meet our significance standard of $P<.05(t(23)=1.495, .1>P>.05$; Cohen's $d=0.59)$. This was, however, the largest positive effect of the intervention seen across the 1.5 years of the study.

In the top two quartiles of Prof. Z's sections, the students in the intervention improved less than students in the control section, so statistical analysis was not performed on this data.

Finally, when comparing the final exam and improvement scores of all students who experienced the intervention and all students in the control sections, we see that students from the control sections consistently did better on the final exam than students in the intervention sections (Cohen's $d=0.37$ across all participants in all sections). This trend holds when just looking at the students in the bottom two quartiles of all students and the top two quartiles in the control and intervention sections. Students in the control sections also improved more between the midterms and the final exam than students in the intervention section. Possible explanations for this trend will be explored in the following section.

\section{Discussion}

Completing the Exam Analysis and Reflection exercise created by Benson and Zhu did not result in statistically significant improvements in student performance on the final exam in an introductory circuits course taken by non-majors. ${ }^{6}$ When comparing the performance of all participating students in two sections taught by the same instructor, with one section receiving the intervention EAR exercise after each midterm exam and the other section completing a control extra problem, students who completed the intervention did show a greater improvement between the midterm exams and the final exam than students who did the control. However, such improvements were not statistically significant, even when looking solely at the bottom two quartiles of the students in each section.

It is possible that the study design led to difficulty in isolating the impact of the EAR. A final exam can sometimes be an imperfect measure of a student's understanding of a certain concept or topic. The stark change in difficulty of the final exam between the two years of the study also 
made comparisons difficult. Relying solely on a single data point to determine the impact of an intervention is a flawed approach, as multiple factors are at work in how a student performs on the final.

Perhaps the most impactful factor which we did not sufficiently control for is instructor quality. In a large course like this, taught across multiple sections by multiple instructors, there will likely be variation in the quality and experience of the instructors. While we did endeavor to control for such variation by comparing the paired intervention/control sections taught in Fall 2015 and Fall 2016 (Data Set A), these data sets were fairly small and potentially suffered from natural variability in student outcomes; this seemed especially likely with the two sections Prof. $\mathrm{Z}$ taught in the Fall of 2016. Turning to the larger data which included students across all sections of the course (Data Set B), it is possible that the control sections faired significantly better than the intervention sections because of differences in the instructors. The two sections in which the control was administered were each taught by an experienced instructor, one of whom had been teaching the course for over a decade. The seven sections in which the intervention was administered had more instructor variation, including three sections taught by adjunct instructors who are potentially of lower teaching ability.

\section{Conclusion}

In conclusion, this quantitative study failed to demonstrate that students who completed a reflection exercise following each of their midterm exams performed significantly better on their final exam than students who completed a control problem.

Various suggestions to improve the impact of reflection on student performance and to study such impacts emerge from this work. While it appears that incorporating reflection into engineering core courses holds great promise, it is possible that reflection must be wide-spread to be truly impactful, frequently incorporated into a course and woven across the curriculum. Incorporating two short reflection exercises into a single course as extra credit did not result in measureable improvements in student understanding.

When it comes to studying the outcomes of such reflection in the future, it may be better to find a means other than the final exam to assess such an intervention. A mixed-methods approach to studying reflection interventions could provide insight into the students' perceptions of reflection and whether it does indeed lead to improved metacognition and conceptual understanding. Combining what Wynne et al. and Benson and Zhu did into a single intervention may lead to improved outcomes. ${ }^{5,6}$ This would involve not only having students reflect on their work and lessons learned but having them rework problems they got wrong on the exam while still using the same approach or similar thought process they had on the exam. Finally, another idea is to keep track of common errors and misunderstood concepts on the exams, using students' selfreflections in the form of the EAR. This would be an extension of Benson and Zhu's original work, which largely focused on these student-identified errors, rather than how the process of reflection impacted students' later understanding and performance (as was the aim of this work). 
Final exam problems could be written to test those misconceptions, in order to measure how students respond and the impact of the reflection that they did. Such ideas will be the focus of future work. 


\section{References}

1. R. S. Adams, J. Turns, and C. J. Atman, "Educating effective engineering designers: The role of reflective practice," Design Studies, vol. 24, no. 3, pp. 275-294, May 2003.

2. N. Cross, "Expertise in design: An overview," Design Studies, vol. 25, no. 5, pp. 427-441, Sep. 2004.

3. L. Jolly, "Challenging hegemony - reflections on reflection," in Proceedings of the 1999 UQ TEDI Conference - Effective Courses/Effective Teaching at University, Brisbane, Australia, 1999.

4. L. Kavanagh, "Reflecting on Reflection - 10 years, Engineering, and UQ," in Australasian Engineering Education Annual Conference, 2008.

5. R. Wynne, "Student Perceptions of Reflective Learning Activities," in Fall 2010 MidAtlantic ASEE Conference, ASEE, 2010.

6. D. Benson and H. Zhu, "Student Reflection, Self-Assessment and Categorization of Errors on Exam Questions as a Tool to Guide Self-Repair and Profile Student Strengths and Weaknesses in a Course," in 122nd ASEE Annual Conference and Exposition, ASEE, 2015.

7. A. Gero, Y. Stav, and N. Yamin, "Increasing motivation of engineering students: Combining "real-world" examples in a basic electric circuits course.” International Journal of Engineering Education, vol. 32, no. 6, pp. 2460-2469, 2016.

8. G. Pitterson, P. Nicole, R. Streveler, and C. Brown, "Exploring undergraduate engineering students' conceptual learning of complex circuit concepts in an introductory course." Frontiers in Education Conference (FIE), 2016.

9. D. Bullock, E.C. Greco, and J.D. Reasoner. "Development of a Small, Robust, and Portable Circuits Training System for an Introductory Course in DC Electrical Circuits," in 2015 ASEE Zone III Conference, 2015.

10. B. Kollöffel and T. Jong, "Conceptual understanding of electrical circuits in secondary vocational engineering education: Combining traditional instruction with inquiry learning in a virtual lab." Journal of engineering education, vol. 102, no. 3, pp. 375-393, 2013.

11. F. Grasso, A. Luchetta, S. Manetti, M.C. Piccirilli, and A. Reatti, "SapWin 4.0-a new simulation program for electrical engineering education using symbolic analysis." Computer Applications in Engineering Education, vol. 24, no.1, pp. 44-57, 2016.

12. Dixon, J.R., New goals for Engineering Education. Mechanical Engineering, 1991. March: p. 56-62.

13. C. Mitchell, L. Jolly, and A. McLeod, "On the way to reflexivity," in Proceedings of the 1998 AaeE Conference - Waves of Change, Gladstone, Australia: AaeE, 1998, pp. 298-299

14. J. Turns, B. Sattler, K. Yasuhara, and J. Borgford-Parnell, "Integrating Reflection into Engineering Education," in 121st ASEE Annual Conference \& Exposition, ASEE, 2014.

15. A. F. McKenna, B. Yalvac, and G. J. Light, "The role of collaborative reflection on shaping engineering faculty teaching approaches," Journal of Engineering Education, vol. 98, no. 1, pp. 1726, Jan. 2009.

16. D. A. Schön, The reflective practitioner: How professionals think in action (arena). Aldershot: Ashgate Publishing, 1991.

17. H. Chen, D. Cannon, J. Gabrio, L. Leifer, G. Toye, and T. Bailey, "Using Wikis and Weblogs to support reflective learning in an introductory engineering design course," in 2005 ASEE Annual Conference, 2015, p. 10.1438.1 - 10.1438.10.

18. W. Navidi, Statistics for Engineers and Scientists. McGraw Hill, 2006. 


\section{Appendix A}

Students were provided with some additional guidelines emphasizing what a quality answer looks like and some common errors to avoid. Below is an example of ideal answers to the prompts.

How my solution is different: The solution provided used the mesh current approach, and I used node voltage. However, I don't think this is necessarily what went wrong. The node voltage method may have worked even better because the problem was asking for the voltage $V_{a}$, which would really be equal to the node voltage.

What went wrong: When I first approached the problem I combined the $3 \mathrm{ohm}, 9 \mathrm{ohm}$, and the branch with the 15/6/6 ohm resistors. This is not right, because the dependent source depends on the current through the 3 ohm resistors. This caused me to get confused because I didn't know how to deal with the dependent source, and I forgot to write a constraint equation for it.

How I can use this in the future: In the future, I will remember to not combine components when the current or voltage through one impacts a dependent source. When I get confused on a problem and realize I do not have all the information I need, I will look back at my earlier approach and see what may have been wrong. This can be a good sanity check for me in the future. I also realized that I have always been confused by constraint equations, and probably need to ask about them in office hours.

In an effort to avoid some common errors, the following information was also presented to the students as encouragement for them to avoid such mistakes:

- How my solution is different

o Literal interpretation of the question ("My answer was 5V, and the correct answer was $3 \mathrm{~V}$. The difference is $2 \mathrm{~V}$.”)

o Failure to describe the differences in approach to the problems.

- What went wrong

o Incorrect description of your process or your mistakes ("I didn’t label my nodes correctly," when really the problem was in voltage division.)

- How I can use this in the future

o Too vague or broad ("I can work more slowly.")

o Lacking specifics about a concept ("I can try to understand the circuits concepts better." - How will you do this? And which concepts?)

- Failure to follow the directions (attaching the exam but ONLY the problems you were reflecting on, reflecting first on the free response if you missed more than 3 points on one/both, otherwise reflecting on a multiple choice problem.). 